\title{
Using the Behaviour Change Wheel to Design an App to Change Tourist Behaviour and Increase Dispersal into Regional Areas
}

\author{
Martha Wells ${ }^{(\sqrt{ })}$ (1), Kristy de Salas (10), and Anne Hardy (1) \\ University of Tasmania, Hobart, Australia \\ \{Martha. Wells, Kristy.deSalas, Anne.Hardy\}@utas.edu. au
}

\begin{abstract}
Currently, many tourism destinations are experiencing greatly reduced tourism due to COVID-19. In order to ensure that regions that wish to engage in tourism can share the benefits of it more equally, and to prevent the predicted future problem of overuse of popular areas once pre-COVID visitor numbers resume, an app to encourage tourists and leisure-seekers to change their behaviour and disperse into regional areas has been developed. The Behaviour Change Wheel was used to define the problem, find suitable intervention functions and design methods of delivery that could increase tourists' capability, opportunity and motivation to disperse farther into regions. The Huon Valley of Tasmania, Australia, was used as a research area. Our application of the Behaviour Change Wheel methodology determined that active engagement in logistic, value-based, and social information has the greatest chance of changing behaviour in this region and a list of Behaviour Change Techniques has been developed and considered in the design of a gamified travel app.
\end{abstract}

Keywords: Mobility · Behaviour change intervention · Gamification · Dispersal

\section{Introduction}

In the wake of ongoing lockdowns in Australia and border closures in the state of Tasmania, hospitality and leisure businesses in regional areas have become increasingly reliant on locals engaging in short intrastate tourism experiences [1]. Before COVID-19, tourist dispersal into regional areas had already been identified as a goal of many tourism destinations [2] and posited as a behaviour that could reduce overcrowding and enhance sustainability [3]. However, barriers to this goal are that tourists may not be aware of the value of local regional areas, nor engage in learning about what nearby areas offer.

To combat this, we set out to determine whether we could design an app, built upon the Tourism Tracer technology [4], that would encourage behaviour change using gamification, thus increasing dispersal throughout the Huon Region of Tasmania.

Gamification refers to the use of game elements in non-game contexts [5]. These elements can be minor additions, such as loyalty points, or be experienced as fullfledged games, and they have been used to enhance experiences, retain engagement, 
and change behaviour. Gamification has been found to generally provide positive results in a meta-review of studies, however, it was most likely to have a neutral or negative effect when researchers were attempting to change user behaviour [6]. This unreliability is generally contributed to poor design that utilises generic points, badges and leaderboards, rather than thoughtful and user-centred design [7]. The former approach means that gamification is relegated to an extrinsic reward system, that can only motivate users' participation so long as they are invested in the rewards, it fails to intrinsically motivate or to solve problems that could lead to change [8].

Gamification technology has been used increasingly often in tourism, although so far the major focus of its implementation has been in experience enhancement within specific destinations, rather than behaviour change [9], the goal of behaviour change via interventions is not new to tourism research and practice. There are a plethora of studies that seek to change tourists' behaviour, ranging from those which use nudge theory to change the environment around tourists to reduce friction and move them towards behaviours such as reducing plate wastage [10] through to those which use the Theory of Planned Behaviour and Value-Belief-Norm Theory to understand factors that contribute to tourist intention and thereby design interventions to elicit environmentally friendly behaviour such as reduced littering in marine protected areas [11]. Likewise, in Gamification studies, Self-determination theory [12] is commonly used to explain how activities can meet individuals' motivational needs and this model is used to design interventions that change behaviour [7].

These frameworks can all be effective in appropriate contexts, however they can also be poor predictors of behaviour in tourism and leisure contexts [13] and methodologies based on them can be poor mechanisms for behaviour change $[14,15]$. The inconsistency of results when utilising designed interventions can be explained by the limitations of each theory; Michie, et al. [16] identified in a systematic review of behaviour change theories that no single framework existed that considered all possible influences on behaviour, or all intervention and policy techniques, and that many theories had components with overlapping definitions, making it difficult to select an appropriate theory in many contexts, or to reproduce results across studies.

In response to this, Michie, et al. [16] created the Behaviour Change Wheel (BCW) from an amalgamation of elements from nineteen behaviour change frameworks which were found to be comprehensive, coherent, and grounded in a behaviour theory. The BCW walks users through the process of designing behaviour change interventions from identifying the problem to selecting effective interventions, to choosing best methods of delivering interventions and allows comprehensive evaluation. Arguably, the advantages the $\mathrm{BCW}$ has over methods created within single behaviour frameworks are that it is comprehensive, and therefore able to be used in broad contexts [16], meaning that the risk of choosing a framework that does not consider a factor that is significant in tourism contexts is absent and it is systemised, and therefore no steps in the evaluation process can be missed.

The BCW was designed within health research and has mostly been used within health contexts to address patient and carer practices [17]. It has also become increasingly common in contexts regarding environmental concerns like energy conservation [18] and to promote physical activity [19], however using it within the 
tourism industry, and to design behaviour change interventions to promote tourist dispersal, is a novel test of the methodology.

Due to the novelty of using gamification in a tourist dispersal context, and the evidence that selective and context-specific design is necessary for successful behaviour change, a comprehensive methodology was necessary to design a gamified intervention system with the prospect of changing behaviour and dispersing tourists. Given that the BCW has been designed to identify and apply methods to encourage behaviour change, and is designed for application in a broad range of contexts [20] it was considered appropriate for application in tourism and this study. To date, BCW has, to the authors' knowledge, not been applied to tourism. The goal of this paper is to outline and critically assess the potential for the application of $\mathrm{BCW}$ to a tourism context.

\section{Methods}

The Behaviour Change Wheel methodology was employed to identify techniques to change behaviour and app components were considered that could administer these techniques. This study intends to use these designed interventions as a new frontend to the already existing Tourism Tracer Technology [4]. This app collects the GPS and survey data of participating tourists, allowing for fine-grained spatiotemporal analysis of tourist mobility, informed by tourists' demographic and preference information [3]. This mixed-methods data has the potential to measure dispersal and attitudes towards the interventions in real-time.

\subsection{BCW Methodology}

The BCW methodology contains three stages: the first involves defining the central behaviour that requires change, and the components of that behaviour that are potentially powerful targets for creating change. The BCW uses the COM-B behaviour system to define these components. COM-b stands for Capability Opportunity Motivation [leads to] Behaviour. COM-b is a system that was created by Michie, et al., in 2011 in response to their initial evaluation of nineteen behaviour change intervention models [16] it was developed to synthesise and simplify their categories of factors that influence behaviour. Physical and psychological capability, physical and social opportunity, and reflective and automatic motivation are all components that this system uses to clarify the drives behind a behaviour, and it is understood that each behaviour will be the result of a web of these components influencing one another, and in turn influencing behaviour. In the second stage, broad intervention functions such as 'training' and 'modelling' are identified and in the third stage, relevant techniques and ways of delivering them are matched to the intervention function and the situation.

\section{Stage 1: Understand the Behaviour}

Step 1: Define the problem in behavioural terms. Defining the problem as a behaviour helps designers clarify the 'who' 'what' and 'where' of the problem. 
Step 2: Select the target behaviour. In this step a list is developed of all potential factors that could contribute to the problem behaviour and analyse them for a) level of impact b) likelihood of behaviour change and c) spill over to other behaviours.

Step 3: Specify the target behaviour. The context of the highest priority target behaviours are clarified so that the most appropriate point of intervention can be found.

Step 4: identifying what needs to change. This step involves using the COM-B model. The COM-B model assumes that all components have some effect on behaviour, however this step finds components that will be most effective at changing the target behaviour. It is not relevant, for instance, to create an intervention that increases motivation to travel to regional areas if tourists are already eager to go, but are physically incapable. In that case, interventions that bridge physical difficulties would be necessary.

\section{Stage 2: Identify Intervention Options}

Step 5: Identify intervention functions. Intervention functions are broad categories of ways in which behaviour can be changed: an intervention based on training will be different to an intervention based on incentivization. The BCW has already identified which COM-B components are effectively targeted by which intervention functions.

Step 6: Selecting Intervention functions. In this step, the APEASE criteria (Affordable, Practical, Effective, Acceptable, Safe and Equitable) is used to select the intervention functions are most practical and ethical to focus on. The APEASE criteria was developed 2014 my Michie et al. to be used as a simple evaluation tool within the BCW [21]. This study used functions only if they met every point of the APEASE criteria.

\section{Stage 3: Identify Content Options}

Step 7: Identifying Behaviour Change Techniques. Using Michie, et al.'s Taxonomy of BCTs [22], Behaviour Change Techniques (BCTs) are identified that have been found to link to the intervention functions selected.

Step 8: Determine mode of delivery. Once BCTs have been identified, we can design app features that use them.

\section{Results}

\subsection{Stage 1: Identify Tourists' Behaviour}

We identified the problem of regional tourism as: Tourists and local leisure-seekers tend to either go to iconic locations and stay on major touring routes or not leave Hobart.

And our Intervention aim: To encourage them to disperse to more diverse locations and regional areas. 
Thirty-two factors were identified that impact this behaviour. The factors that were chosen related to issues such as knowledge of the region, perception of risk, time, money, travel group, peer referrals, social media influence, marketing, weather, ability to travel, physical ability and personal preferences. These were chosen based upon the authors knowledge of the tourism industry in Tasmania [23], the authors' previous research into factors that influence dispersal in Tasmania [3] and research conducted by others authors into factors which effect behaviour such as weather [24, 25] and digital connectivity [26]. Focusing only on factors rated with a high level of potential impact, high likelihood of potential behaviour change, and high level of potential to spill over to other behaviours reduced our list to a small number of promising behaviours to target. Some behaviours, such as perceiving lower ability to mitigate bad weather in regional areas, are accurate assessments, so there is a low chance of changing that behaviour, nor is it reasonable to expect tourists to continue into regional outdoor areas on days where the weather is severe. In other cases, such as tourists lacking adequate transport, the potential impact would be high if we could change it, but it is outside of the scope of this study.

Three target behaviours were found that had promise to change this behaviour, and which were within the scope if this study:

1. Access and engage in logistical information on regional locations: To visit regional areas, tourists and leisure-seekers must be aware of the locations, and the distances and difficulties associated with travel to them. If we can develop the behaviour of exploring and planning with this information in individuals who were not previously, it has potential to increase dispersal to these areas.

2. Access and engage in information that raises the perceived value of regional locations: Besides knowing about locations and how to get to them, tourists must also widely value a location to visit it in significant numbers. If we can develop the behaviour of engaging with a) information on which regional locations are attuned to a personal interest, or b) a new goal system within a game that raises the value of a location, it has potential to increase dispersal to these areas.

3. Access and share social information on regional locations: Learning where others have gone and seeing recommendations from others for new areas as well as sharing information about their own trips are behaviours that can raise the interest and decision making of tourists. One tourists public demonstration of having gone to and enjoyed a regional area could also be useful in changing the behaviour of others.

For all three identified Target Behaviours, the contexts were similar. These behaviours are principally enacted in the planning phase of a trip, although they could also potentially be engaged in while on a trip in the region to add extra stops. The exception was the sharing of social information which can be done in the post-trip reflection stage. All Target Behaviours can be done alone or as a group of travelers.

Next the COM-B components were analysed. These were found to be same for the three target behaviours: the app should change the psychological capability, the social opportunity, and the reflective motivation (Table 1). 
Table 1. COM-B component analysis of target behaviours

\begin{tabular}{l|l|l}
\hline $\begin{array}{l}\text { COM-b } \\
\text { model } \\
\text { components }\end{array}$ & $\begin{array}{l}\text { What needs to happen for the target } \\
\text { behaviour to occur? }\end{array}$ & Is there a need for change? \\
\hline $\begin{array}{l}\text { Capability } \\
\text { Physical }\end{array}$ & $\begin{array}{l}\text { tourists must be able to access and } \\
\text { consume information about } \\
\text { locations and reasons to visit them }\end{array}$ & $\begin{array}{l}\text { No: it is reasonable to expect } \\
\text { tourists are psychically capable of } \\
\text { finding and reading information in } \\
\text { vast majority of cases }\end{array}$ \\
\hline $\begin{array}{l}\text { Capability } \\
\text { Psychological }\end{array}$ & $\begin{array}{l}\text { Tourists know where to look to } \\
\text { access information, remember and } \\
\text { consider possibilities, and make } \\
\text { travel decisions that include } \\
\text { regional locations }\end{array}$ & $\begin{array}{l}\text { Yes: it is currently easy for tourists } \\
\text { to miss seeing regional tourism } \\
\text { information, or to forget it in the } \\
\text { face of more constant highlight } \\
\text { marketing }\end{array}$ \\
\hline $\begin{array}{l}\text { Opportunity } \\
\text { physical }\end{array}$ & $\begin{array}{l}\text { Tourists must have a device and } \\
\text { internet access, or equivalent } \\
\text { physical resources to access } \\
\text { information }\end{array}$ & $\begin{array}{l}\text { No: it is reasonable to expect } \\
\text { tourists have internet access and/or } \\
\text { access to tourism marketing and } \\
\text { books }\end{array}$ \\
\hline $\begin{array}{l}\text { Opportunity } \\
\text { Social }\end{array}$ & $\begin{array}{l}\text { Tourists must be in a similar mind } \\
\text { to travel party members to seek out } \\
\text { information and make travel } \\
\text { decisions together or be inspired to } \\
\text { seek out information by social } \\
\text { interactions that raise their interest }\end{array}$ & $\begin{array}{l}\text { Yes: information accessed should } \\
\text { motivate anyone in travel party, not } \\
\text { just seeker, and information should } \\
\text { not be accessed in a way that pulls } \\
\text { the user out of the moment and } \\
\text { away from socialising on a trip [27] }\end{array}$ \\
\hline $\begin{array}{l}\text { Mourists must be interested and } \\
\text { engaged by the process of learning } \\
\text { about travel to regional locations } \\
\text { and want to seek out the } \\
\text { information }\end{array}$ & $\begin{array}{l}\text { Yes: Tourists do not currently know } \\
\text { where to find this specific } \\
\text { information, and it is often } \\
\text { packaged in a more complicated } \\
\text { and boring way than highlight } \\
\text { marketing }\end{array}$ \\
\hline
\end{tabular}

\subsection{Stage 2: App Intervention Options}

This combination of components corresponded to every intervention function, however in an APEASE review, 'Restriction' and 'Coercion' were not considered as candidates as they are not acceptable or safe, and 'Environmental restructuring' was discounted for being impractical and potentially unacceptable for environmental damage. Therefore, 'Training', 'Modelling', 'Enablement', 'Education', 'Persuasion' and 'Incentivisation' were the selected Intervention Functions.

\subsection{Stage 3: App Content}

Using the intervention taxonomy [22] corresponding BCTs were found and analysed for appropriateness in the tourist context. For this, the APEASE criteria was used again.

As tourism is an innately hedonic activity, interventions were considered appropriate if they added, rather than detracted, from playful and escapist behaviours. therefore "6.1 Demonstration of the behaviour", which requires watching and learning 
rather than participating, was considered an ineffective intervention in this context while "Identification of self as role model" does meet a common need of travellers to gain pleasure from proving competence in an unusual arena [28] (Table 2).

Table 2. Target behaviour change techniques

\begin{tabular}{|c|c|c|}
\hline Target BCT & App element equivalence & $\begin{array}{l}\text { Review with APEASE \& } \\
\text { target behaviours }\end{array}$ \\
\hline 1.1 Goal setting & $\begin{array}{l}\text { Mechanic to view info on locations } \\
\text { and accept them as quests }\end{array}$ & $\begin{array}{l}\text { Simplifies acting on new } \\
\text { knowledge and raises value }\end{array}$ \\
\hline $\begin{array}{l}\text { 1.2 Problem } \\
\text { solving }\end{array}$ & $\begin{array}{l}\text { Info screen on locations includes } \\
\text { what users need to bring (i.e. } \\
\text { protective clothes and water if } \\
\text { outdoors) }\end{array}$ & Raises knowledge \\
\hline $\begin{array}{l}1.4 \text { Action } \\
\text { planning }\end{array}$ & $\begin{array}{l}\text { Suggest pre-planning of trips and } \\
\text { rearrangeable accepted quests to } \\
\text { help tourists plan an itinerary }\end{array}$ & $\begin{array}{l}\text { Simplifies acting on new } \\
\text { knowledge and raises value }\end{array}$ \\
\hline $\begin{array}{l}2.2 \text { Feedback on } \\
\text { behaviour }\end{array}$ & $\begin{array}{l}\text { Statistics/badges for locations } \\
\text { visited by type }\end{array}$ & $\begin{array}{l}\text { Raises value of visiting } \\
\text { locations }\end{array}$ \\
\hline $\begin{array}{l}\text { 2.3 Self-monitoring } \\
\text { of behaviour }\end{array}$ & $\begin{array}{l}\text { Screen: travel map that shows } \\
\text { progress }\end{array}$ & $\begin{array}{l}\text { Raises value and knowledge } \\
\text { of locations }\end{array}$ \\
\hline $\begin{array}{l}2.7 \text { Feedback on } \\
\text { outcomes on } \\
\text { behaviour }\end{array}$ & $\begin{array}{l}\text { Information on help given to small } \\
\text { businesses }\end{array}$ & $\begin{array}{l}\text { Not effective (impact is small, } \\
\text { separate from own goals of } \\
\text { enjoyment) }\end{array}$ \\
\hline 3.1 Social support & $\begin{array}{l}\text { Promote travel-party to work } \\
\text { together with group-friendly } \\
\text { challenges }\end{array}$ & $\begin{array}{l}\text { Raises social satisfaction and } \\
\text { value }\end{array}$ \\
\hline $\begin{array}{l}\text { 4.1 Instruction on } \\
\text { how to perform a } \\
\text { behaviour }\end{array}$ & App tutorial: popup explanations & Raises knowledge \\
\hline $\begin{array}{l}6.1 \text { Demonstration } \\
\text { of the behaviour }\end{array}$ & App tutorial: video/walkthrough & Not effective (uninteresting) \\
\hline $\begin{array}{l}6.2 \text { Social } \\
\text { comparison }\end{array}$ & $\begin{array}{l}\text { Users may plant virtual trees in } \\
\text { locations where they have } \\
\text { completed challenges, other users } \\
\text { can see which locations are widely } \\
\text { visited by tree counts }\end{array}$ & $\begin{array}{l}\text { Raises social satisfaction and } \\
\text { knowledge }\end{array}$ \\
\hline $\begin{array}{l}6.3 \text { Information } \\
\text { about others' } \\
\text { approval }\end{array}$ & $\begin{array}{l}\text { Allow comments/reaction to users } \\
\text { visiting new places }\end{array}$ & Raises social satisfaction \\
\hline 7.1 Prompts/cues & $\begin{array}{l}\text { Map where all are } \\
\text { visible + suggestion popups when } \\
\text { close }\end{array}$ & Raises knowledge \\
\hline $\begin{array}{l}10.3 \text { Reward (self, } \\
\text { social or material) }\end{array}$ & $\begin{array}{l}\text { Extra activities in } \\
\text { locations/collection of apples from } \\
\text { planted trees }\end{array}$ & Raises value of places \\
\hline
\end{tabular}


Table 2. (continued)

\begin{tabular}{l|l|l}
\hline Target BCT & App element equivalence & $\begin{array}{l}\text { Review with APEASE \& } \\
\text { target behaviours }\end{array}$ \\
\hline $\begin{array}{l}\text { 12.5 Adding } \\
\text { objects to the } \\
\text { environment }\end{array}$ & QR codes, caches to find & $\begin{array}{l}\text { Not practical or acceptable: } \\
\text { cannot add to public } \\
\text { spaces/parks }\end{array}$ \\
\hline $\begin{array}{l}\text { 13.1 Identification } \\
\text { of self as role } \\
\text { model }\end{array}$ & $\begin{array}{l}\text { If users 'plant a tree', they can help } \\
\text { other players gain more seeds, will } \\
\text { be told how many players have } \\
\text { picked from their tree }\end{array}$ & Raises social satisfaction \\
\hline $\begin{array}{l}\text { 13.2 Framing and } \\
\text { reframing }\end{array}$ & $\begin{array}{l}\text { Give users challenges/things to } \\
\text { identify and collect in locations to } \\
\text { reframe reason for going }\end{array}$ & Raises value of places \\
\hline $\begin{array}{l}\text { 14.5 Rewarding } \\
\text { completion }\end{array}$ & $\begin{array}{l}\text { Reveal new goals/locations after } \\
\text { they have been to enough locations, } \\
\text { and gained enough clues to solve } \\
\text { puzzle }\end{array}$ & Raises value of places \\
\hline $\begin{array}{l}\text { 15.3 Focus on past } \\
\text { success }\end{array}$ & $\begin{array}{l}\text { Remind of results of previous days } \\
\text { using app with maps/result updates }\end{array}$ & $\begin{array}{l}\text { Not effective (users may not } \\
\text { be capable of going to region } \\
\text { again - e.g. tourists) }\end{array}$ \\
\hline
\end{tabular}
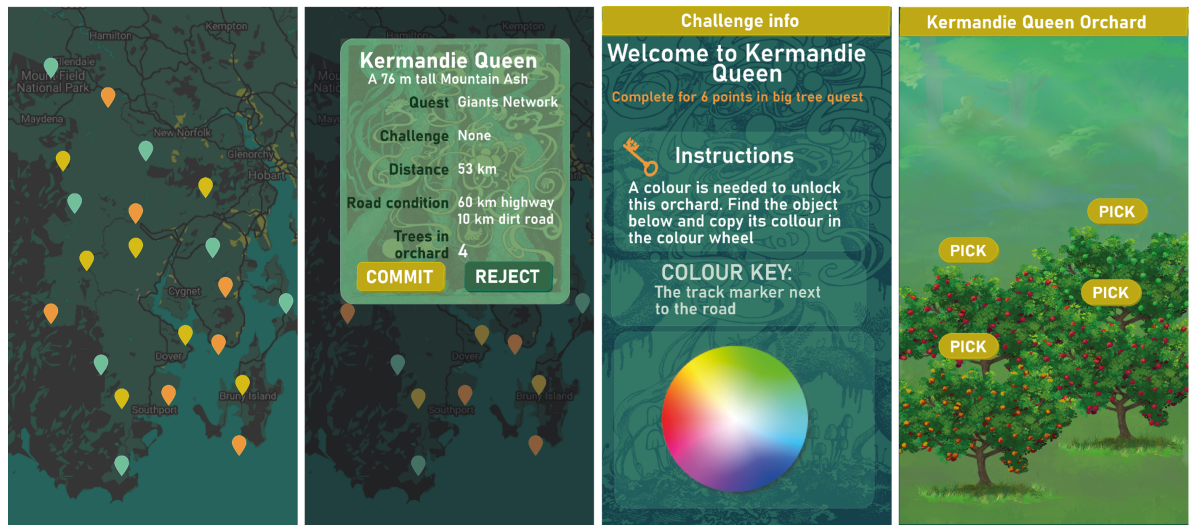

Fig. 1. Prototype designs of app elements.

\section{Discussion}

This study used the BCW methodology to design a gamified app with interventions aimed at changing tourist and leisure-seeker behaviour to disperse into regional areas at a greater rate Fig. 1. BCW has been designed to apply to a broad range of contexts [21] - however, the vast majority of its uses so far have been in health and medicine [17]. 
The application of the BCW makes significant contributions to tourism research. This is the first time that the $\mathrm{BCW}$ has been applied to a hedonic context (tourism). As a result of this, our research has augmented a suite of behaviour change techniques applicable to hedonic environments that can be used by future tourism researchers.

Practically, this research project has developed an app that can be used in other tourism destinations. Its application in Tasmania will assist in dispersing the benefits of tourism beyond 'hotspots', and the gamified aspect of the app will arguably enhance the tourism experience in Tasmania and beyond.

In applying the methodology to tourism, it did prescribe some ineffective Behaviour Change Techniques, and some had to be reconfigured to be more in line with a game element rather than a health intervention. This may be because the ultimate goals of the users are significantly different from the original context of BCW use. In some health interventions, there is a presupposition that the user wants and benefits from the outcomes of the behaviour change but the behaviour is too boring, tedious, or forgettable to incorporate in daily life without intervention, while in the context of dispersal, the intended outcome most benefits area stakeholders and the environment [29]. However, the methodology exhibited advantages, as it allowed for a systematic examination of the process of designing interventions to increase dispersal throughout a regional area, from problem identification to promising content identification in one methodology.

We found $\mathrm{BCW}$ had another advantage over more traditionally used tourism behaviour theories such as the Theory of Planned Behaviour: there has been evidence of an attitude-behaviour gap in tourist behaviour [30] which means that tourists with pro-environmental or social attitudes will still act in self-serving ways on holidays where they are hedonically motivated [14]. By giving equal consideration to all possible influences on behaviour as potential targets, BCW has a level of flexibility that makes it a useful methodology in various circumstances, including tourism, where more hedonic, less commonsense influences can be rated as more impactful.

This process also made it evident that there are many factors inhibiting regional dispersal in which an app cannot intervene. Time constraints, increased dangers associated with remoteness, transport access limitations and undeliverable personal preferences are all factors affecting tourist movement into these areas that this study cannot influence. Future work with a larger scope could work with policymakers and providers to influence some of these, however others, such as time constraints for tourists on fixed schedules are unavoidable impediments.

For tourists and leisure-seekers without these impediments, we found the most promising behaviour to target is their engagement with information, whether logistic, value-based or social. We used Behaviour Change Techniques to design the most engaging method within our limitations to raise people's capability, opportunity and motivation to engage with information on regional areas, and use it to plan trips. With these component prescriptions, an app was prototyped for the Huon Valley Region of Tasmania, Australia. 


\section{References}

1. Tourism Tasmania: T21 Visitor Economy Action Plan 2020-2022, https://www.t21.net.au/_ data/assets/pdf_file/0005/91418/T21-Visitor-Economy-Action-Plan.pdf. Accessed 12 Aug 2021

2. Tourism Research Australia: Beach, Bush and Beyond: Understanding Regional Dispersal of Australian Tourists. https://www.destinationnsw.com.au/wp-content/uploads/2019/10/Under standing-Regional-Dispersal-of-Australian-tourists-October-2019.pdf. Accessed 12 Aug 2021

3. Hardy A, Birenboim A, Wells M (2020) Using geoinformatics to assess tourist dispersal at the state level. Ann Tour Res 82

4. Hardy A et al (2017) Tracking tourists' travel with smartphone-based GPS technology: a methodological discussion. Inf Technol Tour 17(3):255-274

5. Deterding S, Dixon D, Khaled R, Nacke LE (2011) From game design elements to gamefulness: defining "Gamification.” In: Proceedings of the 15th International Academic MindTrek Conference: Envisioning Future Media Environments. Association for Computing Machinery, New York, pp 9-15

6. Hamari J, Koivisto J, Sarsa H (2014) Does gamification work? - a literature review of empirical studies on gamification. In: Proceedings of the Annual Hawaii International Conference on System Sciences. pp 3025-3034

7. Seaborn K, Fels DI (2015) Gamification in theory and action: a survey. Int J Hum Comput Stud 74:14-31

8. Nicholson S (2015) A RECIPE for meaningful gamification. In: Reiners T, Wood LC (eds) Gamification in Education and Business. Springer, Cham, pp 1-20. https://doi.org/10. 1007/978-3-319-10208-5_1

9. Xu F, Buhalis D, Weber J (2017) Serious games and the gamification of tourism. Tour Manage 60:244-256

10. Dolnicar A (2020) Designing for more environmentally friendly tourism. Ann Tour Res 84:102933

11. Martina V, Weiler B, Reis A, Dimmock K, Scherrera P (2017) 'Doing the right thing': how social science can help foster pro environmental behaviour change in marine protected areas. Mar Policy 81:236-246

12. Ryan RM, Deci EL (2000) Intrinsic and extrinsic motivations: classic definitions and new directions. Contemp Educ Psychol 25(1):54-67

13. Rossi AN, Armstrong JB (1999) Theory of reasoned action vs. Theory of planned behavior: testing the suitability and sufficiency of a popular behavior model using hunting intentions. Hum Dimens Wildlife 4(3):40-56

14. Dolnicar S, Cvelbar LK, Grün B (2019) A sharing-based approach to enticing tourists to behave more environmentally friendly. J Travel Res 58(2):241-252

15. Kidd AM et al (2015) The effect of minimum impact education on visitor spatial behavior in parks and protected areas: an experimental investigation using GPS-based tracking. J Environ Manage 162:53-62

16. Michie S, van Stralen MM, West R (2011) The behaviour change wheel: a new method for characterising and designing behaviour change interventions. Implement Sci 6(1)

17. Barker F, Atkins L, de Lusignan S (2016) Applying the COM-B behaviour model and behaviour change wheel to develop an intervention to improve hearing-aid use in adult auditory rehabilitation. Int J Audiol 55:S90-S98

18. Wells L, De Salas K, Lewis I, Berry A (2016) Behaviour change wheel driven normative feedback in a serious game for energy conservation. In: Proceedings of 1st International Joint Conference of DiGRA and FDG. Dundee, Scotland, pp 1-16 
19. Murtagh EM, Barnes AT, McMullen J, Morgan PJ (2018) Mothers and teenage daughters walking to health: using the behaviour change wheel to develop an intervention to improve adolescent girls' physical activity. Publ Health 158:37-46

20. Michie S, West R, Rona C, Brown J, Gainforth H (2014) ABC of Behaviour Change Theories. Silverback, Great Britain

21. Michie S, Atkins L, West R (2014) The Behaviour Change Wheel. A Guide to Designing Interventions, 1st edn. Silverback, Great Britain

22. Michie $\mathrm{S}$ et al (2013) The behavior change technique taxonomy (v1) of 93 hierarchically clustered techniques: building an international consensus for the reporting of behavior change interventions. Ann Behav Med 46(1):81-95

23. Ooi CS, Hardy A (2020) Tourism in Tasmania. Forty South, Hobart

24. McKercher B, Shoval N, Park E, Kahani A (2015) The [limited] impact of weather on tourist behavior in an urban destination. J Travel Res 54(4):442-455

25. Becken S, Wilson J (2013) The impacts of weather on tourist travel. Tour Geogr 15(4):620639

26. Paris CM, Berger EA, Rubin S, Casson M (2015) Disconnected and unplugged: experiences of technology induced anxieties and tensions while traveling. In: Tussyadiah I, Inversini A (eds) Information and Communication Technologies in Tourism 2015. Springer, Cham, pp 803-816. https://doi.org/10.1007/978-3-319-14343-9_58

27. Shen Y, Choi HC, Joppe M, Yi S (2020) What motivates visitors to participate in a gamified trip? A player typology using Q methodology. Tour Manag 78:104074

28. Iso-Ahola SE (1982) Toward a social psychological theory of tourism motivation: a rejoinder. Ann Tour Res 9(2):256-262

29. Goodwin H (2017) The Challenge of Overtourism. Resp Tour Partnership 4, 1-19

30. Juvan E, Dolnicar S (2014) The attitude-behaviour gap in sustainable tourism. Ann Tour Res 48:76-95

Open Access This chapter is licensed under the terms of the Creative Commons Attribution 4.0 International License (http://creativecommons.org/licenses/by/4.0/), which permits use, sharing, adaptation, distribution and reproduction in any medium or format, as long as you give appropriate credit to the original author(s) and the source, provide a link to the Creative Commons license and indicate if changes were made.

The images or other third party material in this chapter are included in the chapter's Creative Commons license, unless indicated otherwise in a credit line to the material. If material is not included in the chapter's Creative Commons license and your intended use is not permitted by statutory regulation or exceeds the permitted use, you will need to obtain permission directly from the copyright holder.

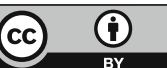

